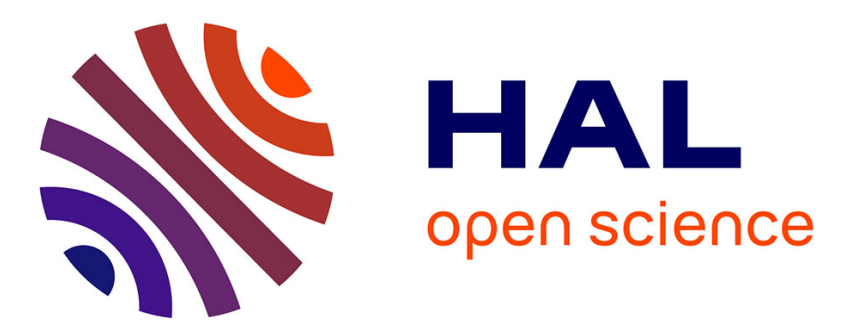

\title{
Non canonical syntactic structures in discourse: tonality, tonicity and tones in English (semi-)spontaneous speech
}

\author{
Laetitia Leonarduzzi, Sophie Herment
}

\section{To cite this version:}

Laetitia Leonarduzzi, Sophie Herment. Non canonical syntactic structures in discourse: tonality, tonicity and tones in English (semi-)spontaneous speech. Interspeech 2013, Aug 2013, Lyon, France. pp.1453-1457. hal-01510224

\section{HAL Id: hal-01510224 \\ https://hal.science/hal-01510224}

Submitted on 19 Apr 2018

HAL is a multi-disciplinary open access archive for the deposit and dissemination of scientific research documents, whether they are published or not. The documents may come from teaching and research institutions in France or abroad, or from public or private research centers.
L'archive ouverte pluridisciplinaire HAL, est destinée au dépôt et à la diffusion de documents scientifiques de niveau recherche, publiés ou non, émanant des établissements d'enseignement et de recherche français ou étrangers, des laboratoires publics ou privés. 


\title{
Non-canonical Syntactic Structures in Discourse: Tonality, Tonicity and Tones in English (Semi-)spontaneous Speech
}

\author{
Laetitia Leonarduzzi, Sophie Herment \\ Aix Marseille Université, Laboratoire Parole et Langage, UMR 7309, 13100 Aix-en-Provence, France \\ laetitia.leonarduzzi@univ-amu.fr, sophie.hermenteuniv-amu.fr
}

\begin{abstract}
This paper presents a corpus study of four non-canonical English structures used for information packaging extrapositions, right dislocations, $i t$-clefts, $w h$-clefts. We study the relations between the information structure and the prosodic patterns (tonality, tonicity and tones) and show that the canonical (expected) prosody of these structures is not the most frequent one in semi-spontaneous speech, meaning that the canonical use of these structures might not be canonical at all in terms of frequency. It is argued that in discourse the pragmatic functions of the non-canonical structures studied derive from the complex interactions between syntax and prosody. Tonality reveals the informativeness (relevance at this point of discourse) of each part of the structure, adding meaning to that of the syntactic structure. Inside the intonation phrase, tonicity indicates what is old or new information, sometimes countering the canonical use of syntax, and can be used for highlighting or contrastive purposes. As for tones, their function is to mark contrast, emphasis or implication on the part of the speaker.
\end{abstract}

Index Terms: prosody; syntax; discourse; information structure; extraposition; right dislocation; it-cleft; $w$ h-cleft.

\section{Introduction}

The information structure of a sentence can be expressed both through prosody and the use of a particular syntactic structure, for instance non-canonical structures such as cleft sentences. Four structures of that kind are studied here: extrapositions, right dislocations, it-clefts and $w h$-clefts. The question addressed is the following: what happens prosodically when such structures are used? The aim of this paper is to study the way the prosody/syntax interface functions. Linguists often determine the prosodic pattern of a syntactic structure on the basis of its information structure. One syntactic structure is generally described as corresponding to one (at most two) specific prosodic pattern(s). In discourse, it is clearly more complex and meaning partly springs from the subtle interactions between the syntactic structures and the prosodic patterns. In the present study, a detailed prosodic analysis coupled with a discourse analysis are conducted in order i) to test how frequently the expected (canonical) prosodic patterns are used in discourse and ii) when a non-canonical pattern is found, to determine what the role of prosody is.

\section{Corpus and method}

Drawing on the oral component (mostly dialogues) of ICE-GB [1] (a syntactically parsed corpus of spontaneous speech in British English), to which we added various examples all taken from (semi-)spontaneous speech, we conducted two separate analyses which were then combined: a prosodic analysis and a discourse analysis. The queries on the corpus resulted in the examination of a total of 86 extrapositions, 66 right dislocations, 154 it-clefts and 152 whclefts. Due to the poor acoustic quality of many examples in ICE-GB, the prosodic analysis was conducted aurally.

\subsection{Non-canonical syntactic structures}

The structures studied are grouped under the term noncanonical syntactic structures in the sense that they can be considered as a reorganization of the canonical order. Four structures are considered:

- Extrapositions: they are traditionally analysed as a reorganisation of the canonical order of the sentence, with a movement of the subject (or object) clause from its normal position to a position at or near the end of the sentence [2] [3] [4].

It's clear who they are.

- Noun-phrase right dislocations (henceforth RDs): a noun phrase appears at the right of the sentence and its canonical position is filled by a co-referential pronoun [4] [5].

It looks swollen that foot.

- Two types of clefts:

it-clefts: It's John who broke the vase.

wh-clefts: What we want is peace.

A cleft sentence is classically considered as coming from a simple clause (here John broke the vase or We want peace) which has been divided into two separate sections, each containing its own verb [6] [7] [3] [4].

Each of the structures analysed is composed of two parts:

- Extrapositions: the main clause (it is clear) and the extraposed clause (who they are).

- Right dislocations: the clause itself (it looks swollen) and the dislocated element (that foot).

- it-clefts: the first part with the focused element (It's John) and the relative clause (who broke the vase).

- wh-clefts: the wh-clause (what we want) and the predicate (is peace).

This distinction is essential for the prosodic analysis (2.2).

\subsection{Prosodic analysis}

We follow the British tradition here and in particular, the systems known as the three Ts, tonality, tonicity and tone [8].

Tonality is the chunking, the division into tone units, or intonation phrases. Indeed, following phonologists like [9] or [10], we consider that an intonation phrase (IP) is a segment of speech which occurs with a coherent prosodic contour (pitch and rhythm). Phonetic clues make it possible to segment the discourse into IPs: the presence of pauses (silent or not), an anacrusis at the beginning of the IP, the lengthening of the final syllable of the IP and pitch reset (see [10] [11] [12]). Following [13], we consider that there is only one level of 
boundary, associated with the intonation phrase. IP boundaries are marked by slashes in the examples. For the present study, we focused on the presence or absence of an IP boundary between the two parts of the structures. We coded 1 IP when there was no boundary and 2 IPs when a boundary was present at that particular place. If there is an IP boundary elsewhere in the structure, it is not considered relevant here: example (23) below is coded as 2 IPs (it contains three in fact, one in the first part and two in the second part).

Tonicity is the place of the nuclear accent. The principle that there is only one nuclear syllable in an IP is adopted. It is the most prominent one, that bearing the tone (the distinctive pitch movement) of the IP (see for example [14] or [15]). The nucleus bears on the last lexical item of the IP. If it moves left, then it is considered as marked. The nuclear syllable is underlined in the examples below. When the structure is pronounced in a single IP, we coded - F (F standing for Fall, but it could be another tone, see below) when the tonic is found in the second part of the structure and $\mathrm{F}$ - if the tonic is in the first part.

The tone is the distinctive pitch-movement. The symbols used are $\mathrm{F}$ for a simple fall, $\mathrm{R}$ for a simple rise, $\mathrm{HF}$ for high fall and FR for fall-rise, which are the most common tones in English. The first two tones are neutral, the last two are not, and referred to as marked in the present paper.

What we shall call the canonical prosodic pattern is the pattern commonly acknowledged by linguists and which corresponds to the canonical use of the syntactic structure in terms of information structure. It slightly varies according to the structure under consideration, but in any case the pattern is made up of 1 IP and a neutral tone (F or R). What differs according to the syntactic structure is the place of the tonic (on the first or second part of the structure, see section 3 ).

\subsection{Discourse analysis: information structure}

The common point between the structures analysed is that they are concerned with information packaging [3] [16] [17] [5]. A separate discourse analysis of the corpus was conducted, the context being closely looked at in order to confront the information structure found in discourse to the notions found in the literature on the structures.

Following [18] [19], we consider that information can be discourse-old (given: having been previously mentioned in the discourse) or hearer-old (known: shared knowledge). These two notions are opposed to, respectively, discourse-new and hearer-new information.

Extrapositions: the extraposed element is generally discourse-new information (but not always) [20] [21]. Extraposition is mandatory when the content of the extraposed clause is discourse-new [20] [21] [5].

Right dislocations: the content of the dislocated element is always discourse-old [5].

Clefts: clefts are syntactically analysed as focusing structures in English [22] [8] [18] [7]. They contain a foregrounded element $\mathrm{FE}$, or focus (John, peace in the examples above) and a presupposition PP (who broke the vase, what we want) [3]. The PP is defined as an open proposition (for instance John broke $x$ ) and the FE is a value assigned to the variable in that open proposition (the vase) [3] [7]. In whclefts, the presupposition has to represent information that the speaker can assume the hearer is thinking about, and thus matches the notion of old or given information. In it-clefts, the PP also canonically represents old information [18].

\section{Results}

For each structure, the results of the prosodic analysis are given in a table. The third column refers to the examples below the tables.

\subsection{Extrapositions}

What can be considered as the canonical prosodic pattern for extrapositions is one IP, with the tonic in the second part of the sentence in a neutral position and with a neutral tone (Fall or Rise) (represented by - F). Indeed, in extrapositions the extraposed element is canonically new, and hence should be accented (see for instance [3] [23]).

Table 1: Extrapositions

\begin{tabular}{|c|c|c|c|}
\hline & & Ex & $\%$ (tokens) \\
\hline \multicolumn{2}{|c|}{ Canonical prosody (- F) } & 1 & $43 \%(37)$ \\
\hline \multicolumn{2}{|l|}{ Non-canonical prosody } & & $57 \%(49)$ \\
\hline 1 IP & Marked tonic (- F) & 2 & $10.5 \%(9)$ \\
& Marked tone (HF) & 3 & $1 \%(1)$ \\
2 IPs & F/F & 4 & $18.5 \%(16)$ \\
& FR/F (+/- marked tonic) & 5 & $13 \%(11)$ \\
& $\mathrm{HF} /(\mathrm{H}) \mathrm{F}$ & 6 & $14 \%(12)$ \\
\hline Total & & & $100 \%(86)$ \\
\hline
\end{tabular}

(1) I mean it'd been left to me to organize it F

(2) Then it doesn't matter who's involved F

(3) I never realised how hard it is to talk HF

(4) I mean at that stage / it might not have been made official $\mathrm{F} /$ that you need to be from the from the family of Aaron $\mathrm{F}$

(5) So it 's important FR/ that every time a product leaves one of these stages $\mathrm{F} /$ that it works properly $\mathrm{F}$

(6) But someone who 's who 's computing / they forget how difficult it is HF / for you to understand anything HF

\subsection{Right dislocations}

The dislocated element in noun phrase right dislocations is said to be outside the nucleus of the clause [3] [24], and always corresponds to old information, so canonical prosody in this case means one IP with a tonic on the last accented element of the core sentence with an $\mathrm{F}$ tone, and a deaccented dislocated element (F -).

Table 2: Right Dislocations

\begin{tabular}{|c|c|c|c|}
\hline & & Ex & $\%$ (tokens) \\
\hline \multicolumn{2}{|c|}{ Canonical prosody (F-) } & 7 & $44 \%(29)$ \\
\hline \multicolumn{1}{|l|}{ Non-canonical prosody } & & $56 \%(37)$ \\
\hline 1 IP & Marked tone FR - & 8 & $16.5 \%(11)$ \\
& Marked tone and tonic HF - & 9 & $1.5 \%(1)$ \\
& Marked tonic F - & 10 & $3 \%(2)$ \\
2 IPs & F/F & 11 & $23 \%(15)$ \\
& F/F marked tonic & 12 & $6 \%(4)$ \\
& HF/HF +/- marked tonic & 13 & $4.5 \%(3)$ \\
& FR/R & 14 & $1.5 \%(1)$ \\
\hline Total & & & $100 \%(66)$ \\
\hline
\end{tabular}

(7) It's a bit scary this F 
(8) It looks swollen that foot FR

(9) This does not sound like Dickens to me the bit you've given us HF

(10) A good run that $F$

(11) It is very odd $\mathrm{F} /$ this whole aspect of code switching $\mathrm{F}$

(12) And it got out F/ this poor wasp F

(13) It's just amazing HF/ the way she's so quick at picking up the music HF

(14) Is that something you saw FR / this piece of jagged metal R/ or something you assumed must be there FR

\subsection{It-clefts}

In $i t$-clefts, the first part of the structure contains the focused element, and the rest of the structure is presupposed and corresponds to discourse-old information. If prosodic focus corresponds to syntactic focus, then a canonical prosody means one IP with a tonic on the last accented syllable of the focused element, with a neutral tone $(F)$, the rest of the sentence being deaccented (see stressed-focus it-clefts [18]).

Table 3: It-clefts

\begin{tabular}{|c|c|c|c|}
\hline & & $\mathrm{Ex}$ & $\%$ (tokens) \\
\hline \multicolumn{2}{|c|}{ Canonical prosody (F-) } & 15 & $11 \%(17)$ \\
\hline \multicolumn{2}{|c|}{ Non-canonical prosody } & & $88.9 \%(137)$ \\
\hline 1 IP & $-\mathrm{F}$ & 16 & $19.5 \%(30)$ \\
2 IPs & F/F & 17 & $46.7 \%(72)$ \\
& F marked tonic /F & 18 & $11 \%(17)$ \\
& HF/F or FR/(H)F & 19 & $11.7 \%(18)$ \\
\hline Total & & & $100 \%(154)$ \\
\hline
\end{tabular}

(15) it's the nasal retina that that decussates F

(16) So so you mean that it's the nerves that feed them F

(17) It is the system F/ that is responsible F

(18) It's the second Monday F / that we get back from Easter holiday $\mathrm{F}$

(19) a. Indeed it may be because they are ideals HF/ and not truths F/that they are so deeply attached to them F b. It's not the nasal field FR / that decussates F

\subsection{Wh-clefts}

A wh-cleft starts with the presupposed part, the focus being at the end of the structure. The prosody of a $w h$-cleft is canonical when there is one IP with a neutral tone $(\mathrm{F})$ at the end of the second part of the structure $(-\mathrm{F})$.

Table 4: wh-clefts

\begin{tabular}{|c|c|c|c|}
\hline & & Ex & $\%$ (tokens) \\
\hline \multicolumn{2}{|c|}{ Canonical prosody (- F) } & 20 & $8 \%(12)$ \\
\hline \multicolumn{2}{|c|}{ Non-canonical prosody } & & $92.1 \%(140)$ \\
\hline 2 IPs & F/F & 21 & $49.3 \%(75)$ \\
& FR/F & 22 & $28.3 \%(43)$ \\
& FR/F marked tonic & 23 & $9 \%(14)$ \\
& R/F & 24 & $5.5 \%(8)$ \\
\hline Total & & & $100 \%(152)$ \\
\hline
\end{tabular}

(20) What you have to do is maybe check F

(21) When I said we've got the right mistake what I meant really $\mathrm{F} /$ was that we've now got a pair of examples $\mathrm{F}$
(22) So what one wonders is FR / what went on in his mind $\mathrm{HF}$

(23) What I want FR / is some new people FR / telling me some new lies $\mathrm{F}$

(24) What matters now R/ is not what the police do $\mathrm{F} /$ but how they do it $\mathrm{F}$

\section{Discussion}

What can be seen first of all from the figures in the tables above is that in our data the canonical prosodic patterns of the four structures analysed do not correspond to the most common prosodic patterns. It is striking when we consider cleft sentences ( $8 \%$ and $11 \%$ of the examples for $i t$-clefts and $w h$-clefts respectively). This means that what is considered as the canonical use for these structures might not be, in terms of frequency, canonical at all. So what does the confrontation between the prosodic and the discourse analyses tell us about the use of these structures?

\subsection{Tonality and informativeness}

We claim that when there are 2 IPs associated with an F/F pattern, then it means that each part of the structure is informative. The notion of informativeness is to be distinguished from that of old/new information such as defined in 2.3. An item is informative when it is relevant at this point of discourse. Conversely, it is uninformative when it is not relevant at this point of discourse. This notion sometimes matches that of old/given information but not always. An item can be given, but important for the speaker at a particular point of discourse: it is informative.

One might think that the presence of two (or more) IPs in the sentence (independently of the tones) is due to its length (for instance (5)), but this is not necessarily the case. Quite short occurrences uttered with two IPs can be found, not only with RDs (12) but also in the more complex structures, for instance (17). There is more than just length involved here. In (17), the presupposition someone is responsible has just been mentioned in another cleft, so it is discourse-old, but the speaker decides to make it a highpoint in her discourse (see [16] for that notion). For her, it is informative. If the speaker had pronounced only 1 IP with F -, she would have decided to highlight only the contrastive focus (the system). The presupposed part would not have been prosodically highlighted and would have truly corresponded to old information not worth underlining again. This is what happens in (15), where (something) decussates is a presupposition that has just been mentioned by the same speaker (see (19b)).

2 IPs with an F/F pattern say more than the canonical prosodic pattern associated with the structure does. It reveals the informativeness of both parts of the structure. It is clear with RDs. In (11), even if this whole aspect of code switching is discourse-old (it is even the theme of the discourse), the speaker needs to make sure that the co-speaker has understood the reference of it and adds a dislocated element which is pronounced with a separate IP. The $\mathrm{F} / \mathrm{F}$ pattern is quite frequent when the RD aims at clarifying the reference of the co-referential pronoun, or is an afterthought [25]. In both cases, the element is informative. The fact that with RDs the most common prosodic pattern is not the canonical one, while RDs are all discourse-old, shows that the notion of givenness is not sufficient to account for the structure. 
The same is true of clefts. With it-clefts, if the presupposition is new and the focus old (which is the case in clefts used for transition, such as It is then that...), one might expect 1 IP with - F, but the pattern is always 2 IPs, which again is an indication that givenness is not a satisfactory explanation for the number of IPs. Informativeness is at stake. In (19b), the speaker (presumably a teacher) underlines that it is important not to mix up the nasal field and the retina as far as decussation is concerned. In that case, both field and decussates are relevant elements in the discourse at that point, and that is what is indicated by the second IP on that decussates (this kind is close to informative-presupposition itclefts [18], or all-new it-clefts [26] [27]). Conversely in (15), which takes up (19b), we find the canonical pattern with one IP, the presupposition now being clear. In the $w h$-cleft (21), the speaker has been misunderstood and mean is important here, hence the separate IP for the presupposition. This could be called an "all-informative $w h$-cleft", though not in the sense of "all-new" but of "all-relevant" [28].

$\mathrm{F} / \mathrm{F}$ extrapositions can also be analysed in the same way. In (4), the question is why the Aaronites ruled over the Levites. The content of the extraposed clause is old information (it has just been mentioned by the co-speaker), but it is nevertheless pronounced in a separate IP because it is relevant at this point. The content of the predicate is also informative (it is new here) and is announced in a separate IP as well.

With clefts, the presence of 2 IPs associated with $\mathrm{F}$ tones adds meaning to the syntactic structure. The syntax of clefts is concerned with focus and presupposition. Tonality for its part expresses the informativeness (or not) of each part of the structure. With right-dislocations, tonality indicates the pragmatic function of the structure, depending on the informativeness of the dislocated element. As for extrapositions, their function is to answer the principle of endweight or end-focus [3]. Tonality reveals which part of the structure (extraposed clause and/or main clause) is informative.

\subsection{Tonicity and givenness}

Tonicity is concerned with old and new information at the level of the IP. As already mentioned, independently of the number of IPs, a displaced nucleus indicates that what follows is old information. This is what happens at the level of the sentence in the canonical pattern of it-clefts: the nucleus is not at the end of the IP and the second part (the presupposition) is old. When a nucleus is displaced (not on the last lexical item of the IP), it can serve to highlight an element, as in the case of extrapositions: in (2) who is the main point of the speaker, (somebody) is involved being given in the context. Very often the word bearing the nuclear tone becomes contrastive. For instance in (23) the nucleus on $I$ makes it contrastive. The same thing happens in (10) or (18). Tonicity is also sometimes a tool to highlight the speaker's emotional attitude. In (12) the nucleus on poor means that the speaker is sorry for the wasp.

With $i t$-clefts, the canonical pattern is F -, with one IP and a nucleus on the focus, what follows being deaccented. If the nucleus falls on the presupposed part instead of the focus, then prosody counters the syntactic structure, showing that everything is actually old information. In (16), the noncanonical prosody indicates that this cleft is only used for recapitulation (the speaker only sums up what the co-speaker just said). The cleft here plays a part at the level of the organization of discourse. It is not used in a canonical way (to mark contrast). This type of "all-given" it-clefts is less acknowledged in the literature.

\subsection{Non neutral tones}

\subsubsection{Emphatic $H F$}

The non neutral tones can have various functions. With itclefts, if the HF tone falls on the focus, it will serve to highlight the focalisation which is already present through the syntactic structure (in that case it is in accordance with syntax): in (19a) it highlights a contrast. The HF tone can also express the speaker's attitude (such as emphasis) (22). In extrapositions it is likewise used for emphatic purposes (6).

\subsubsection{Implicational and contrastive $F R$}

The FR tone indicates a particular attitude of the speaker towards their speech (see [10] among others). It is a nonneutral tone and according to the structure it can have various meanings. With an RD such as (8), it involves greater implication on the part of the speaker (for instance empathy with the co-speaker). This also holds for it-clefts. In (19b), the presence of the FR tone on the first part of the cleft underlines the speaker's warning to be careful not to mix up the nasal field and the retina. With a $w h$-cleft, its function is to draw the attention of the co-speaker on the second part of the structure (the focused element) [23] [29] [30] [28]. The first part of the cleft then brings in little information (in spite of the presence of a separate IP). In (22), what one wonders has no particular importance. What is relevant is the end of the sentence, and this is marked by the FR tone in the first IP (the $w h$-clause). The same is true for extrapositions (5).

More classically, the FR tone can also be used as an indication of contrast (see [10] [14] among others), as in (14) (RD) where saw is opposed to assumed or in (23) (wh-cleft).

\section{Conclusion}

This study shows that the canonical uses of the structures under consideration are not in fact canonical in terms of frequency, as revealed by prosody. Indeed, the canonical prosodic patterns are not the most frequent ones.

Prosody can be in accordance with syntax and highlight focalization or contrast in clefts for instance, or counter it to bring in new meaning. It can play a part at two levels, either by telling us what the discourse function of the structure is (RDs), or by revealing its information structure in terms of informativeness (tonality) or givenness (tonicity). Tonality plays a part at the level of the sentence (2 IPs associated to the $\mathrm{F} / \mathrm{F}$ pattern indicating that both parts of the structure are informative) and tonicity at the level of the IP - whether the IP corresponds to the whole sentence or not. The tones come into play at yet another level. They can be used for emphatic (HF) or contrastive (FR) purposes. Depending on the structure, the FR tone can also have various functions, but is very often implicational.

This study mainly bears on the relations between prosody and information structure. Prosody can have other functions not mentioned here but which are worth investigating, for instance at the level of the interaction -such as indicating that an RD is a "discourse-filler" (F/F) - or at the level of the discourse presuppositions (contradicting the opinion of other speakers) (FR). 


\section{References}

[1] Aarts, B. \& Nelson, G., "Investigating English around the world: The International Corpus of English", in R. Wheeler (ed.), The workings of language: from prescriptions to perspectives, 107115, New York, Praeger, 1999. ICE-GB: http://ice-corpora.net/ ice/icegb.htm (University College London)

[2] Rosenbaum, P., The Grammar of English Predicate Complement Constructions, Cambridge, MA: MIT Press, 1967.

[3] Huddleston, R. \& Pullum, G.K., The Cambridge Grammar of the English Language, Cambridge: Cambridge University Press, 2002.

[4] Crystal, D., A Dictionary of Linguistics and Phonetics, Malden: Blackwell Publishing, 1980/2003.

[5] Birner, B. \& Ward, G., "Information Structure and Noncanonical Syntax", in Horn, L.R. \& Ward, G. (eds.), The Handbook of Pragmatics, 153-174, Oxford: Basil Blackwell, 2004.

[6] Jespersen, O., Analytic Syntax, London: Allen and Unwin, 1937.

[7] Lambrecht, K., "A framework for the analysis of cleft constructions", Linguistics 3(3): 463-516, 2001.

[8] Halliday, M.A.K., Intonation and Grammar in British English, The Hague-Paris: Mouton, 1967.

[9] Crystal, D., Prosodic Systems and Intonation in English, Cambridge: Cambridge University Press, 1969.

[10] Cruttenden, A., Intonation, Cambridge: Cambridge University Press, 1986.

[11] Couper-Kuhlen, E., An Introduction to English Prosody, Tübingen: Niemeyer, 1986.

[12] Deschamps, A., Duchet, J-L., Fournier, J-M., O’Neil, M, English Phonology and Graphophonemics, Paris: Ophrys, 2004.

[13] Grabe, E., Post, B. \& Nolan, F., "Modelling intonational variation in English. The IViE system", in S. Puppel \& G. Demenko (eds.), Proceedings of Prosody 2000, Adam Mickiewitz University, Poznan, Poland, 2001.

[14] Tench, P., The Intonation Systems of English, London: Cassell, 1996.

[15] Halliday, M.A.K. \& Greaves, W.S., Intonation in the Grammar of English, London / Oakville: Equinox, 2008.

[16] Quirk, R., Greenbaum, S., Leech, G. \& Svartvik, J., A Comprehensive Grammar of the English Language, London: Longman, 1985, $12^{\text {th }}$ edition 1994

[17] Lambrecht, K., Information Structure and Sentence Form: topic, focus and the mental representation of discourse referents, Cambridge: Cambridge University Press, 1994.

[18] Prince, E., "A comparison of WH-clefts and IT-clefts in discourse," Language, Journal of the Linguistic Society of America 54(4): 883-906, 1978.

[19] Prince, E., "The ZPG letter: subjects, definiteness, and information-status", in W. Mann \& S. Thompson (eds.) Discourse Description: Diverse Linguistic Analyses of FundRaising Text, 295-326, Amsterdam: Benjamins, 1992.

[20] Kaltenbök, G., "Using non-extraposition in spoken and written texts: a functional perspective", in Aijmer, K. \& Stenström, A-B. (eds.), Discourse Patterns in Spoken and Written Corpora, 219242, Amsterdam - Philadelphia: John Benjamins, 2004.

[21] Miller, P., "Discourse constraints on extraposition from subject in English" Linguistics: an interdisciplinary journal of the language sciences, vol.39, $\mathrm{n}^{\circ} 4$ : 683-701, Berlin: de Gruyter, 2001

[22] Chomsky, N., Deep Structure, Surface Structure and Semantic Interpretation, IUCL, 1969, reprinted in Chomsky, N., Studies on Semantics in Generative Grammar, The Hague: Mouton, 1972.

[23] Wells, J.C., English Intonation: an Introduction, Cambridge: Cambridge University Press, 2006

[24] Michaëlis, L., \& Lambrecht, K., "Toward a construction-based theory of language, the case of nominal extraposition", Language 76 (2), 219-245, 1996.

[25] Leonarduzzi, L. \& Herment, S., "The Limits between Extrapositions and Right-Dislocations", CERCLES, to appear.
[26] Hedberg, N., "The referential status of clefts", Language 76(4): 891-920, 2000.

[27] Huber, S., "The complex functions of it-clefts", in Molnár, V. \& Winkler, S. (eds.), The Architecture of Focus, 549-578, Berlin, New-York: Mouton De Gruyter, 2006.

[28] Herment, S. \& Leonarduzzi, L., "The Pragmatic Functions of Prosody in English Cleft Sentences", Proceedings of the $6^{\text {th }}$ International conference on Speech Prosody (Shanghai, China): 713-716, 2012.

[29] Gussenhoven, C., The phonology of tone and intonation, Cambridge: Cambridge University Press, 2004.

[30] Brazil, D., The communicative value of intonation in English, Birmingham Bleak House and ELR. 1985, Republished Cambridge: Cambridge University Press, 1997. 